\title{
Seasonal growth dynamics and resilience of the green tide alga Cladophora coelothrix in high-nutrient tropical aquaculture
}

\author{
Pedro H. de Paula Silva*, Rocky de Nys, Nicholas A. Paul \\ School of Marine and Tropical Biology, James Cook University, Townsville Queensland 4811, Australia
}

\begin{abstract}
Two distinct climatic seasons in the tropics generate extreme environmental fluctuations in land-based aquaculture and corresponding challenges for integrated aquaculture. Here we assessed the influence of environmental and culture variables on productivity of Cladophora coelothrix at multiple scales, firstly in an operational settlement pond and subsequently in laboratory and flow-through mesocosm experiments. Classification and regression tree (CART) analyses were used to partition the influence of key variables on growth. In situ productivity correlated primarily with nitrogen concentration, position in the pond and stocking density, with a lesser influence of salinity, temperature and the ratio of nitrate-nitrogen $\left(\mathrm{NO}_{3}{ }^{-}-\mathrm{N}\right)$ and total ammonium nitrogen (TAN). We subsequently evaluated the resilience of C. coelothrix in laboratory and mesocosm environments by manipulating salinity, temperature and nutrients across a broader range of values derived from a year-long survey of the settlement pond. Here temperature had the greatest influence on growth, followed by nitrogen concentration and salinity. Growth rates of $C$. coelothrix were high, irrespective of season, except at the extremes of each season, for example, at the lowest annual temperature and with the combination of high temperature and low salinity. Growth was also limited by $\sim 20 \%$ when $\mathrm{NO}_{3}{ }^{-}$-N and TAN were available simultaneously. The use of CART analyses for both in situ and controlled environment data provided a formal dissection of the relative contribution of each environmental variable to growth, demonstrating the year-round potential for bioremediation and identifying the critical combinations of environmental variables for management of this system.
\end{abstract}

KEY WORDS: Integrated multi-trophic aquaculture - Bioremediation - Classification and regression tree $\cdot \mathrm{CART} \cdot$ Macroalgae $\cdot$ Seaweed $\cdot$ Settlement pond

\section{INTRODUCTION}

High levels of inorganic nutrients (nitrogen and phosphorus) are present in many anthropogenically impacted environments, including intensive aquaculture (Sarà 2007, Lin \& Fong 2008, Abreu et al. 2009). Arguably the most effective method to remove dissolved inorganic nutrients from aquatic environments is through the integrated culture of algal biomass, in particular for point-source discharge from land-based aquaculture (Crab et al. 2007, reviewed by Troell 2009). However, a major constraint on integrated aquaculture is the selection of robust algal species which are effective across seasonal fluctuations in the environment and are also responsive to aquaculture operational cycles, that is, species which are productive through both peak and off-peak production (Neori et al. 2004).

Green tide algae are typically coastal or estuarine species which form opportunistic blooms under eutrophic conditions, sometimes at staggering scales (Lavery \& McComb 1991, Raven \& Taylor 2003, Pang 
et al. 2010). In the past, green tide algae have been considered pest species in the targeted culture of high-value seaweeds (Fletcher 1995, Paul \& de Nys 2008). More recently, green tide algae have instead been targeted to treat aquaculture effluents because of their nuisance characteristics (de Paula Silva et al. 2008). These are primarily rapid growth rates, an ability to use multiple sources of nitrogen and a broad environmental tolerance (Pedersen \& Borum 1997, Taylor et al. 2001). This recent emphasis on high-productivity biomass for integrated aquaculture is warranted given a new focus on algal biomass for diverse and innovative bioenergy applications, such as biocrude (Zhou et al. 2010) and biochar (Bird et al. $2011,2012)$. It is unclear, however, how characteristics unique to tropical land-based aquaculture, in particular monsoonal fluctuations in temperature and salinity with high nitrogen concentrations present in multiple sources (ammonium and nitrate), will influence year-round productivity of green tide algae. In natural settings, complex interactions exist between environmental factors and nitrogen, leading to dynamic growth responses of species which can explain patterns of abundance (Lotze \& Worm 2002). For example, Ulva (Enteromorpha) intestinalis is more resilient in low salinity $(15 \%)$ when nitrogen concentration is high $(>150 \mu \mathrm{M}$ of nitrate-N), rather than low

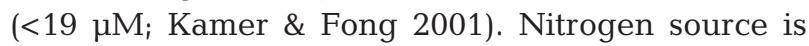
also a driver of productivity, as ammonium can inhibit nitrate uptake even at low concentrations (see Dortch 1990 and Raven et al. 1992 for comprehensive reviews). These examples demonstrate the need to understand species-specific responses to interactions between key factors under environmental conditions relevant to land-based aquaculture in order to optimise algal productivity and bioremediation and to produce a reliable supply of biomass.

The present study, therefore, quantifies the productivity, resilience and, by extension, the bioremediation potential of Cladophora coelothrix Kützing in an operational settlement pond receiving effluents from intensive finfish aquaculture. We evaluated growth of this green tide alga at multiple scales, with a 4 mo in situ experiment, a controlled environment experiment in the laboratory and a flow-through outdoor mesocosm experiment. This combination of in situ and controlled environment data provided a comprehensive assessment of the factors which drive productivity of a green tide alga in an integrated aquaculture system. The in situ data provided a correlative assessment of algal productivity relative to marked changes in environmental conditions across a 4 mo period. We subsequently simulated annual variation in environmental variables (temperature, salinity and nutrients) relevant to this tropical landbased aquaculture system in order to test the growth and resilience of C. coelothrix in 2 controlled experiments. Classification and regression tree analyses were used for interpretation of these complex data sets, providing comparisons of the relative importance of environmental variables for the growth of this green tide alga.

\section{MATERIALS AND METHODS}

\section{Environmental parameters monitoring in situ}

The present study was conducted at Good Fortune Bay Fisheries Ltd., an intensive saltwater barramundi Lates calcarifer Bloch farm located at Bowen, northern Queensland, Australia (latitude $20.02^{\circ} \mathrm{S}$, longitude $148.22^{\circ} \mathrm{E}$ ). This site is located in the dry tropics and is characterized by a wet season (during austral summer) followed by a dry season (austral winter). The primary bioremediation area at the farm consists of a 5 ha settlement pond receiving the effluent water from intensive finfish cultivation. Seasonal and spatial variations in the physicochemical properties of the effluent water in the settlement pond were determined by water quality measurements taken every $2 \mathrm{wk}$ from May 2008 to April 2009 (Table 1). Temperature $\left({ }^{\circ} \mathrm{C}\right)$ and salinity $(\%)$ were measured using a multi-parameter probe (Oakton model PCD 650). Samples were consistently taken at 8 fixed collection points around the settlement pond, $\sim 3 \mathrm{~m}$ from the edge and at a depth of $\sim 30 \mathrm{~cm}$ (Site 1 closest to the inlet and Site 8 closest to the outlet). Nitrogen was measured from water samples taken at the same 8 sites. These samples were filtered through cellulose membrane filters (Sartorious, Minisart $0.45 \mu \mathrm{m}$ ) and placed on ice for transportation to the laboratory, where they were stored at $-20^{\circ} \mathrm{C}$. Nitrogen analysis was done with a Hach colorimeter (Model DR/890) following the prescribed methods: total ammonia nitrogen (TAN) was analysed using the salicylate method and nitrate-nitrogen and nitritenitrogen $\left(\mathrm{NO}_{\mathrm{x}}{ }^{-}-\mathrm{N}\right)$ were analysed simultaneously using a cadmium reduction technique. However, since nitrite is rapidly oxidized to nitrate, the nitrogen enrichments used in the controlled experiments were nitrate-nitrogen $\left(\mathrm{NO}_{3}{ }^{-}-\mathrm{N}\right)$ and/or TAN. The farm is located at a latitude $20.02^{\circ} \mathrm{S}$ in the tropics, and has a yearly average of light availability of $1000 \mu \mathrm{mol}$ photons $\mathrm{m}^{-2} \mathrm{~s}^{-1}$ (calculated from the global solar exposure from the Australian Bureau of Meteorology, www.bom.gov.au/climate/data). 
Table 1. Mean values $( \pm 1 \mathrm{SD}, \mathrm{n}=8)$ of environmental variables (temperature and salinity) and concentrations of total inorganic nitrogen (Tot. nit.), total ammonia nitrogen (TAN) and $\mathrm{NO}_{\mathrm{x}}{ }^{-}-\mathrm{N}\left(\mathrm{NO}_{2}{ }^{-}-\mathrm{N}+\mathrm{NO}_{3}{ }^{-}-\mathrm{N}\right)$ at the study site from May 2008 to April 2009. Note: settlement pond was dry throughout October 2008. Temp: Temperature

\begin{tabular}{|c|c|c|c|c|c|c|c|c|c|c|c|}
\hline \multirow[t]{2}{*}{ Variables } & \multirow[b]{2}{*}{ May } & \multirow[b]{2}{*}{ Jun } & \multirow[b]{2}{*}{ Jul } & \multirow{2}{*}{$\begin{array}{r}2008 \\
\text { Aug }\end{array}$} & \multirow[b]{2}{*}{ Sep } & \multirow[b]{2}{*}{ Nov } & \multirow[b]{2}{*}{ Dec } & \multirow[b]{2}{*}{ Jan } & \multirow{2}{*}{$\overline{F e b}^{20}$} & \multirow[b]{2}{*}{ Mar } & \multirow[b]{2}{*}{ Apr } \\
\hline & & & & & & & & & & & \\
\hline $\operatorname{Temp}\left({ }^{\circ} \mathrm{C}\right)$ & $25.3 \pm 0.3$ & $23.5 \pm 0.4$ & $25.8 \pm 0.3$ & $24.6 \pm 0.3$ & $28.3 \pm 0.2$ & $33.9 \pm 0.3$ & $31.3 \pm 0.6$ & $28.5 \pm 0.3$ & $29.4 \pm 0.5$ & $29.2 \pm 0.5$ & $27.1 \pm 0.2$ \\
\hline Salinity (\%o) & $31.7 \pm 0.2$ & $32.1 \pm 0.6$ & $31.3 \pm 0.3$ & $33.5 \pm 0.4$ & $40.5 \pm 0.3$ & $40.2 \pm 0.6$ & $37.4 \pm 0.4$ & $30.4 \pm 0.6$ & $17.7 \pm 0.6$ & $20.2 \pm 0.6$ & $31.6 \pm 0.4$ \\
\hline Tot. nit. $(\mu \mathrm{M})$ & $47.9 \pm 12$ & $37.1 \pm 14$ & $55.7 \pm 15$ & $70.7 \pm 10$ & $67.9 \pm 15$ & $87.1 \pm 17$ & $80.7 \pm 10$ & $95.7 \pm 12$ & $81.4 \pm 15$ & $82.1 \pm 12$ & $76.4 \pm 10$ \\
\hline $\mathrm{NO}_{\mathrm{x}}{ }^{-}-\mathrm{N}(\mu \mathrm{M})$ & $32.1 \pm 10$ & $26.4 \pm 07$ & $36.4 \pm 11$ & $47.9 \pm 12$ & $39.3 \pm 10$ & $50.7 \pm 10$ & $43.6 \pm 10$ & $51.4 \pm 10$ & $53.4 \pm 12$ & $50.7 \pm 13$ & $43.6 \pm 08$ \\
\hline TAN $(\mu \mathrm{M})$ & $15.7 \pm 05$ & $10.7 \pm 10$ & $19.3 \pm 08$ & $22.9 \pm 15$ & $18.6 \pm 18$ & $36.4 \pm 13$ & $37.1 \pm 12$ & $43.5 \pm 22$ & $30.0 \pm 15$ & $31.4 \pm 11$ & $32.9 \pm 12$ \\
\hline $\mathrm{NO}_{\mathrm{x}}{ }^{-}-\mathrm{N}: \mathrm{TAN}$ & $2.0: 1$ & $2.5: 1$ & $1.9: 1$ & $2.1: 1$ & $2.1: 1$ & $1.4: 1$ & $1.2: 1$ & $1.2: 1$ & $1.8: 1$ & $1.6: 1$ & $1.3: 1$ \\
\hline
\end{tabular}

\section{Algal biomass collection}

The green tide alga Cladophora coelothrix has a broad geographic range, from temperate to tropical climates, predominantly in Europe and Australia (Guiry \& Guiry 2012). It forms a large bloom in the settlement pond of Good Fortune Bay Fisheries Ltd. that is most pronounced in the second half of the year, from June through to December. C. coelothrix was sampled in May 2009 from the dense floating mats in the pond. Samples were collected by hand and restocked in experimental plots (Expt 1, below) or placed in seawater with aeration for controlled environment experiments (Expts 2 and 3). Isolated cultures were maintained for 2 mo before conducting the experimental trials in outdoor aquaria on a recirculating system $\left(\sim 28^{\circ} \mathrm{C}, 36 \%\right.$ ) at the Marine and Aquaculture Research Facilities Unit (MARFU) at James Cook University, Townsville, Australia.

\section{Expt 1: in situ biomass productivity}

Productivity of Cladophora coelothrix was measured for $4 \mathrm{mo}$, from June to September 2008 over the winter season, at 8 positions around the settlement pond. This culture period provided marked variation in environmental conditions relative to annual variation (see Table 1). Three experimental plots containing different densities were located at each of the 8 sites. The densities used in this experiment $\left(0.25,0.5\right.$ and $1 \mathrm{~kg} \mathrm{~m}^{-2}$ fresh weight) were based on the growth/harvest model by de Paula Silva et al. (2008). The culture units $\left(1 \mathrm{~m}^{2}, 15 \mathrm{~cm}\right.$ deep) were made by attaching plastic oyster trays (XL6 Aquatray, Tooltech Pty Ltd) to PVC pipe for flotation, which were then anchored by pickets to the periphery of the pond. Culture units were stocked with freshly collected samples, after excess water had been removed using a hand-operated salad spinner. No aeration or other agitation was provided to the cultures.

Productivity was analysed for a $14 \mathrm{~d}$ growth cycle at the start of each month, from June to September 2009. Biomass was completely harvested from each culture unit, spun-dry and weighed using a digital scale (Adam APFL 4000). Sub-samples of each unit were oven dried for $48 \mathrm{~h}$ at $60^{\circ} \mathrm{C}$ to determine the fresh to dry weight ratio (on average $\mathrm{FW}$ :DW $=3.5$ ). Productivity ( $\mathrm{p}_{\text {; }}$ in $\mathrm{g} \mathrm{DW} \mathrm{m}^{-2} \mathrm{~d}^{-1}$ ) was then calculated using Eq. (1):

$$
\mathrm{p}=\left\{\left[\left(W_{\mathrm{f}}-W_{\mathrm{i}}\right) / \mathrm{FW}: \mathrm{DW}\right] / A\right\} / T
$$

where $W_{\mathrm{i}}$ is the initial biomass, $W_{\mathrm{f}}$ is the final biomass, FW:DW is the fresh to dry weight ratio (3.5), $A$ is the area of culture unit $\left(1 \mathrm{~m}^{2}\right)$ and $T$ is the number of days in culture (14 d).

\section{Expt 2: interactive effects of temperature, salinity and nitrogen (concentration and source) on growth}

The values for temperature, salinity and nitrogen (concentration and source) for the controlled environment experiments were derived from the in situ annual survey of the settlement pond (see Table 1). The potential interactions between these factors were evaluated using a factorial design, where the nitrogen sources $\left(\mathrm{NO}_{3}{ }^{-} \mathrm{N}\right.$ or $\left.\mathrm{TAN}\right)$ were added as single sources to the culture medium at 4 relevant nitrogen concentrations: low $(35 \mu \mathrm{M})$, average $(70 \mu \mathrm{M})$, high $(105 \mu \mathrm{M})$ and very high $(210 \mu \mathrm{M})$, with the latter included as the maximum permitted discharge concentration in Australia (equivalent to $3 \mathrm{mg} \mathrm{l}^{-1}$; Department of Environment and Resource Management 2011). The salinity levels selected represented the annual average of $32 \%$, as well as the extreme values in the wet season $(17 \%)$ and dry season $(40 \%)$ (Table 1$)$. Three consecutive $10 \mathrm{~d}$ experiments (1 d apart) were run at 24,28 and $33^{\circ} \mathrm{C}$ using a controlled environment 
test chamber (Sanyo Model MLR 351), reflecting the average $\left(28^{\circ} \mathrm{C}\right)$ and seasonal extremes in water temperature (see Table 1).

Culture media were prepared using a base of sterile seawater (32\%) with low inorganic nutrients concentration $\left(\mathrm{NO}_{\mathrm{x}}{ }^{-}-\mathrm{N} \quad 3.5 \mu \mathrm{M}\right.$; $\mathrm{TAN} \quad 0.0 \mu \mathrm{M}_{i} \mathrm{PO}_{4}{ }^{3-}$ $0.65 \mu \mathrm{M})$. Salinities $<32 \%$ were diluted with distilled water, and the background nitrogen and phosphorus levels were restored to previous levels. Artificial sea salts without nitrogen (Aquasonic) were added to increase salinity. Culture media $(f / 2$; Guillard \& Ryther 1962) were prepared without nitrogen. Ammonium $\left(\mathrm{NH}_{4} \mathrm{Cl}\right)$ or nitrate $\left(\mathrm{KNO}_{3}\right)$ was then added to respective treatments to give nitrogen concentrations of $35,70,105$ and $210 \mu \mathrm{M}$ (equating to approximately $0.5,1,1.5$ and $3 \mathrm{mg} \mathrm{l}^{-1}$ ).

Prior to experiments the algal samples were rinsed and cleaned to remove any surface contaminants and epiphytes, and maintained for $5 \mathrm{~d}$ at $28^{\circ} \mathrm{C}$ with $150 \mu \mathrm{mol}$ photons $\mathrm{m}^{-2} \mathrm{~s}^{-1}$, in a $12 \mathrm{~h}$ light:12 $\mathrm{h}$ dark photoperiod, in seawater (36\%) with $\mathrm{f} / 2$ medium renewed daily. Algae were kept in batch culture to expose them to the same nutrient concentration prior to experiments. Samples of $100 \mathrm{mg}$ FW were taken from the stock culture and placed into culture vessels (120 ml clear plastic; Techno Plas) containing $100 \mathrm{ml}$ of growth media ( $\mathrm{n}=3$ for each salinity $\times$ nitrogen concentration $\times$ nitrogen source). Culture vessels were randomly allocated a position within the environmental test chamber, with a controlled light intensity of $150 \mu \mathrm{mol}$ photons $\mathrm{m}^{-2} \mathrm{~s}^{-1}$, a photoperiod of $14 \mathrm{~h}$ light:10 h dark, and constant temperature $(24,28$, or $33^{\circ} \mathrm{C}$, in consecutive experiments). Samples were repositioned daily to limit any potential artefacts from light variation within the chamber. Culture media in all vessels were replaced on Day 5, with a total growth period of $10 \mathrm{~d}$. Algal biomass was measured at the beginning and after $10 \mathrm{~d}$, and growth was calculated as daily growth rates (DGR; \% $\mathrm{d}^{-1}$ ) using Eq. (2):

$$
\operatorname{DGR}=\left[\left(W_{\mathrm{f}} / W_{\mathrm{i}}\right)^{(1 / T)}-1\right] \times 100
$$

where $W_{\mathrm{i}}$ is initial fresh weight, $W_{\mathrm{f}}$ is final fresh weight and $T$ is the number of days in culture.

\section{Expt 3: interactive effects of single and multiple nitrogen sources with salinity on growth}

Both ammonium and nitrate are available to varying degrees within the pond and throughout the year (see Table 1). The effect of different ratios of nitrogen sources on growth is potentially important but could not be effectively evaluated at the laboratory scale.
To test the effect of different nitrogen ratios $\left(\mathrm{NO}_{3}{ }^{-}-\right.$ $\mathrm{N}$ :TAN) on growth we instead used an outdoor flowthrough system to simulate the conditions in the settlement pond by maintaining specific nitrogen ratios throughout the experiment. The experimental design comprised of 2 single source nitrogen treatments, $\mathrm{NO}_{3}{ }^{-}-\mathrm{N}$ or TAN (1:0 and 0:1), and 3 multiple nitrogen sources in different $\mathrm{NO}_{3}{ }^{-}-\mathrm{N}:$ TAN ratios $(3: 1,1: 1$ and 1:3). All treatments had nitrogen concentrations over saturation levels $(105 \mu \mathrm{M})$ according to Expt 2 (see 'Results'). Two salinities (17 and 32\%o) were used to represent the wet and dry seasons from the seasonal survey ( $\mathrm{n}=3$ for each nitrogen ratio $\times$ salinity).

The flow-through system consisted of 10 raised 701 sumps, supplying a constant gravity feed of $1 \mathrm{~V}$ (volume) $\mathrm{h}^{-1}$ to $220 \mathrm{ml}$ culture vessels (clear plastic; Techno Plas) containing an initial mass of $100 \mathrm{mg}$ FW. Sumps were refilled twice a day to maintain flow rates. Media for each treatment were prepared as for Expt 2. Dechlorinated tap water $\left(\mathrm{NO}_{\mathrm{x}}{ }^{-}-\mathrm{N} 7 \mu \mathrm{M}\right.$; TAN $\left.0.0 \mu \mathrm{M} ; \mathrm{PO}_{4}{ }^{3-} 0.65 \mu \mathrm{M}\right)$ was used to prepare $17 \%$ culture media, and background levels of phosphate and nitrate were restored. Stocks of $\mathrm{NH}_{4} \mathrm{Cl}$ and $\mathrm{KNO}_{3}$ were used to make both single and multiple nitrogen source treatments, and fresh nutrient media were prepared daily. Culture vessels were repositioned daily to avoid any potential effects of variable flow rates, temperature and light in the experiment. Stock biomass was acclimated in batch culture for $5 \mathrm{~d}$ prior to the experiment, as before. Daily growth rates (DGR) were calculated over $8 \mathrm{~d}$ of culture, according to Eq. (2).

Temperature and light intensity were measured daily. Temperature (minima and maxima) was measured using 4 thermometers spaced throughout the culture area. Light intensity was measured hourly from 07:00 to 18:00 $\mathrm{h}$ on the first day (using a LiCor Li 250 meter), and then subsequently at 07:00,12:00 and 18:00 $\mathrm{h}$ on remaining days. Average $( \pm 1 \mathrm{SD})$ daily temperature and surface irradiances (photosynthetically active radiation; PAR) over the course of the experiment were $26 \pm 5^{\circ} \mathrm{C}$ and $981 \pm 192 \mu \mathrm{mol}$ photons $\mathrm{m}^{-2} \mathrm{~s}^{-1}$, respectively. Salinity was also monitored daily using an Oakton P650 multi-parameter probe.

\section{Statistical analyses}

Classification and regression trees (CART) were used to analyse the data from the in situ and controlled environment experiments using the TreesPlus software (De'ath 2002). We ran univariate CART analyses to explain variation in a single response vari- 
able (productivity in Expt 1 and DGR in Expts 2 and 3) by multiple explanatory variables. Expt 1 had a combination of variables that were categorical (site, month and density) or continuous (total nitrogen concentration, temperature, salinity and nitrogen ratio). Expts 2 and 3 were comprised only of categorical variables (temperature, salinity, nitrogen concentration and source, and salinity and nitrogen ratios, respectively). CARTs explain variation using a stepwise process which splits explanatory variables in a pairwise manner to create homogenous clusters of data (De'ath \& Fabricius 2000). The branch splits minimize the sums of squares (SS) within groups, which is equivalent to a least-squares linear model. Pruning of the final tree was made by 10 -fold cross-validation to develop a simple predictive model (De'ath \& Fabricius 2000). In our analyses, fifty 10 -fold cross validations were performed, and the 'best' tree (minimum estimated cross-validated [CV] error) was selected as the final model for each experiment (see Figs. 1a, 3a \& 5a). These analyses identified the relative importance of explanatory variables involved in complex interactions for each model (see Figs. 1b, 3b \& 5b).

Missing values where culture units were lost during Expt 1 were omitted from the CART analysis, and the surrogate function in TreePlus was disabled. The data sets for each experiment were plotted in 2 ways, firstly as the tree from the CART analysis (mean values and number of replicates are listed below each of the terminal nodes) and, secondly, as the means for relevant main effects for each experiment (see Figs. 2, 4 \& 6).

\section{RESULTS}

\section{Environmental parameters monitoring in situ}

There were large temporal variations in both temperature and salinity in the settlement pond (Table 1). Annual averages of temperature and salinity were $28^{\circ} \mathrm{C}$ and $32 \%$, respectively. In the wet season (during austral summer, November to March) temperature was high and salinity low and the extremes of these variables were $33^{\circ} \mathrm{C}$ and $17 \%$, respectively (Table 1). Conversely, in the dry season (austral winter, June to September) temperature was lower and salinity higher, with extreme values at $24^{\circ} \mathrm{C}$ and $40 \%$, respectively (Table 1). Both nitrogen concentration and source varied throughout the year and between sites within the settlement pond. The annual average for total inorganic $\left(\mathrm{NO}_{\mathrm{x}}^{-}-\mathrm{N}+\mathrm{TAN}\right)$ nitrogen concentration was $70.3 \mu \mathrm{M}\left(43.2 \mu \mathrm{M} \mathrm{NO}_{\mathrm{x}}{ }^{-}\right.$-
$\mathrm{N}$ and $27.1 \mu \mathrm{M}$ TAN ; Table 1 ). The highest mean nitrogen concentration across the 8 sites sampled was recorded in January (austral summer, peak production) at $94.9 \mu \mathrm{M}\left(51.4 \mu \mathrm{M} \mathrm{NO}_{\mathrm{x}}{ }^{-}-\mathrm{N}\right.$ and $43.5 \mu \mathrm{M}$ TAN; Table 1), while the lowest level of nitrogen recorded was in June (austral winter, off-peak production) at $37.1 \mu \mathrm{M}\left(26.4 \mu \mathrm{M} \mathrm{NO}_{\mathrm{x}}{ }^{-} \mathrm{N}\right.$ and $10.7 \mu \mathrm{M}$ TAN; Table 1). $\mathrm{NO}_{\mathrm{x}}{ }^{-}-\mathrm{N}$ was always present at a higher concentration than TAN throughout the year, with $\mathrm{NO}_{\mathrm{x}}{ }^{-}-$ $\mathrm{N}$ :TAN ratios varying, on average, from $1.2: 1$ to $2.5: 1$ (Table 1). Individual sites within the pond showed variation from a low of 1.3:1 at Site 1 in June through to a high of 14.6:1 at Site 8 in August.

\section{Expt 1: in situ biomass productivity}

Cladophora coelothrix had sustained productivities in situ. Stocking density was the most important split for higher nitrogen concentrations in the CART ( $>42.5 \mu \mathrm{M}_{i}$ Fig. $1 \mathrm{a}$; branches to the right). The stocking density of $1 \mathrm{~kg} \mathrm{~m}^{-2}$ yielded the highest productivities overall, particularly in the month of August (8.5 $\left.\mathrm{g} \mathrm{DW} \mathrm{m}^{-2} \mathrm{~d}^{-1}\right)$, whereas lower stocking densities had lower productivities 4.2 and $5.9 \mathrm{~g} \mathrm{DW} \mathrm{m}^{-2} \mathrm{~d}^{-1}$ (0.25 and $0.5 \mathrm{~kg} \mathrm{~m}^{-2}$, respectively) except for Site 1, which was closest to the inlet point (Fig. 1a). Productivity in the settlement pond correlated with all of the explanatory variables in the model ${ }_{i}$ however, the relative importance of each factor varied (Fig. 1b). The CART model (58\% of the variability explained) revealed that total nitrogen concentration (NC $100 \%$ ) was the main driver of productivity and was correspondingly the first branch in the tree, splitting replicates with $>42.5 \mu \mathrm{M}$ from those $<42.5 \mu \mathrm{M}$ (Fig. 1a). The position within the pond (Site), the stocking density (Den) and the months (Mon) in which they were cultured also influenced productivity in situ $(79.7,70.6$ and $65.2 \%$ relative to the nitrogen concentration, respectively; Fig. 1b). However, the influence of each of these variables depended on nitrogen concentration. For example, 'Site' was the most important split for low nitrogen concentrations, grouping Sites 1 to 5 and 6 to 8 with mean productivities of 4.3 and $2.5 \mathrm{~g} \mathrm{DW} \mathrm{m}^{-2} \mathrm{~d}^{-1}$, respectively (Fig. $1 \mathrm{a}$; branches to the left). Moreover, even though salinity and temperature varied substantially over 4 mo (32 to $40 \%$ and 24 to $28^{\circ} \mathrm{C}$ from June to September, respectively), these factors had the least influence on productivity ( 40.5 and $35.1 \%$, respectively), while the ratio $\mathrm{NO}_{\mathrm{x}}{ }^{-}-\mathrm{N}$ :TAN had the lowest overall relative importance at $28.2 \%$ (Fig. $1 \mathrm{~b}$ ). None of these 3 variables influenced the splits in the tree. 
a
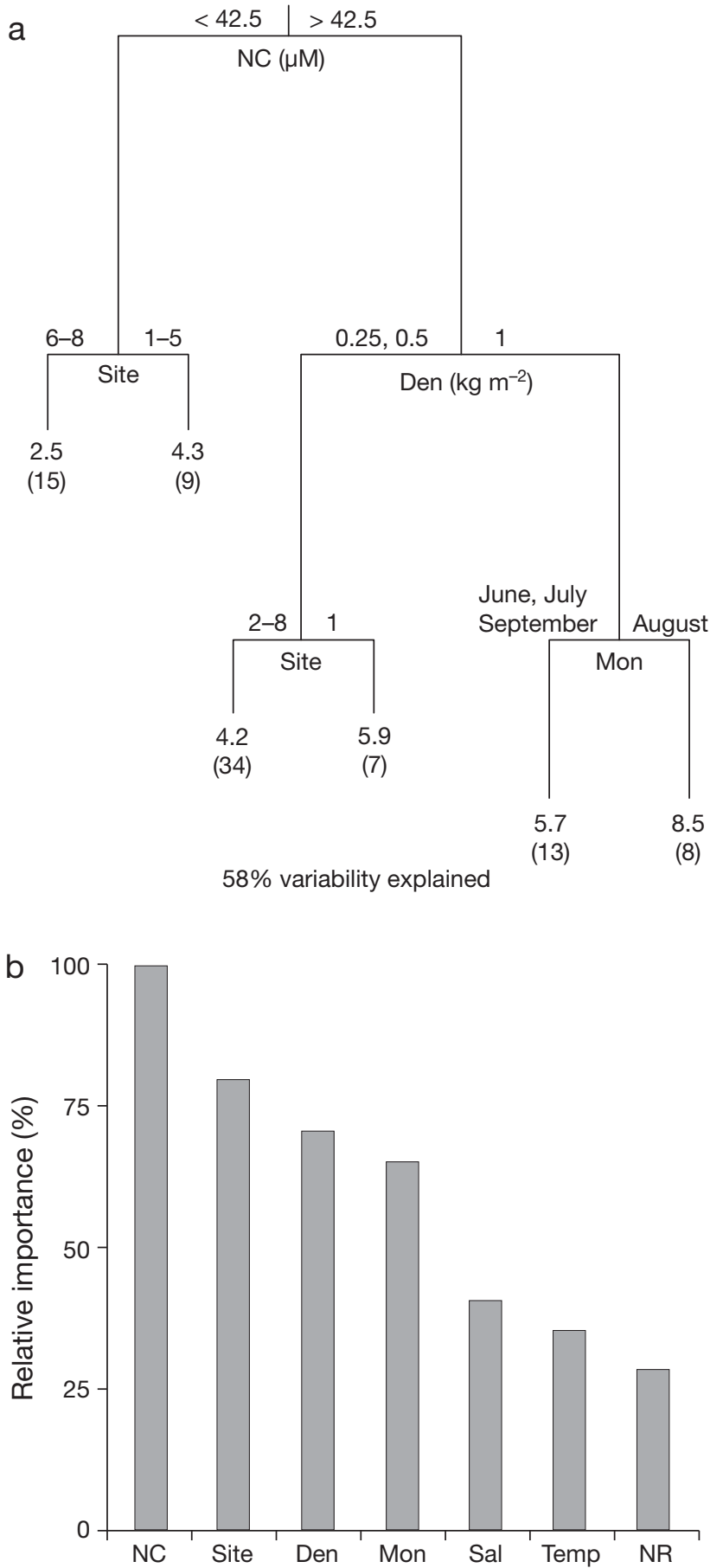

Fig. 1. (a) Univariate classification and regression tree explaining $58 \%$ of the variability in the model. The model is based on the productivity in different months (Mon), positions within the pond (Site) and stocking densities (Den), under different environmental conditions of temperature (Temp), salinity (Sal), nitrogen concentrations (NC) and nitrogen sources ratios (NR). Numbers below terminal nodes are the mean productivity $\left(\mathrm{g} \mathrm{DW} \mathrm{m} \mathrm{m}^{-2} \mathrm{~d}^{-1}\right.$ ) for the specific interaction of explanatory factors, and numbers in brackets indicate the number of cases. (b) Relative importance of all explanatory factors for Cladophora coelothrix productivity in situ
Nitrogen concentration at the sites followed a clear trend, from highest at the inlet through to lowest at the outlet for each of the months (Fig. 2a). Overall, nitrogen concentration was lowest in June and increased steadily through to September; however, the largest differences in nitrogen concentration between months were found at the inlet sites, in particular Site 1 adjacent to the inlet (Fig. 2a). This differentiation between Site 1 and the remaining sites also corresponded to a split in the tree with a higher productivity at Site 1 (5.9 $\mathrm{g} \mathrm{DW} \mathrm{m}^{-2} \mathrm{~d}^{-1}$ ) compared to Sites 2 to 8 (4.2 $\mathrm{g} \mathrm{DW} \mathrm{m}^{-2} \mathrm{~d}^{-1}$ ) under high nitrogen with lower stocking densities of 0.25 and $0.5 \mathrm{~kg} \mathrm{~m}^{-2}$ (Fig. 1a).

In general, the site within the pond influenced productivity in a consistent way over the months. The productivity across all densities for Sites 1 to 5 was on average $70 \%$ higher than productivity at Sites 6 to 8 $\left(\sim 5.4 \pm 0.28\right.$ and $3.2 \pm 0.37 \mathrm{~g} \mathrm{DW} \mathrm{m}^{-2} \mathrm{~d}^{-1}$, respectively) (Fig. 2b). Furthermore, average in situ productivity across all sites increased between the months of June to September, with a clear effect of stocking density in August and September (Fig. 2c), corresponding to the same split in the tree above (Fig. 1a; right side). This effect correlated with an increase in nitrogen concentration over months (Table 1). In June and July, when nitrogen was lower (37.1 and $55.7 \mu \mathrm{M}$, respectively), there was no obvious difference in productivity across the 3 densities tested $\left(\sim 3.8 \pm 0.19\right.$ and $\sim 4.0 \pm 0.27 \mathrm{~g} \mathrm{~m}^{-2} \mathrm{~d}^{-1}$, respectively; Fig. 2c). For the months of August and September, in which the nitrogen concentration was higher $(\sim 70 \mu \mathrm{M})$, productivity was greater for the 2 higher stocking densities tested (Fig. 2c). Productivity of algal cultures with stocking densities with $1 \mathrm{~kg} \mathrm{~m}^{-2}$ reached a peak productivity in August (8.5 $\mathrm{g} \mathrm{DW} \mathrm{m}^{-2}$ $\mathrm{d}^{-1}$; see also this mean value in the CART diagram in Fig. 1a), while at lower stocking densities $\left(0.5 \mathrm{~kg} \mathrm{~m}^{-2}\right)$ the peak productivity was reached in September (Fig. 2c). No difference was found for cultures stocked with $0.25 \mathrm{~kg} \mathrm{~m}^{-2}$ in all months, indicating that there were no growth-limiting factors for the low density treatment (Fig. 2c).

\section{Expt 2: interactive effects of temperature, salinity and nitrogen (concentration and source) on growth}

Cladophora coelothrix daily growth rates varied from a maximum of $8.3 \% \mathrm{~d}^{-1}$ at lower temperatures and nitrogen concentrations $>70 \mu \mathrm{M}$, irrespective of salinity (Fig. 3a; right branches), to a minimum of $2.9 \% \mathrm{~d}^{-1}$, at high temperature, low salinity and nitrogen concentrations $\leq 105 \mu \mathrm{M}$ (Fig. 3a; branches to the 

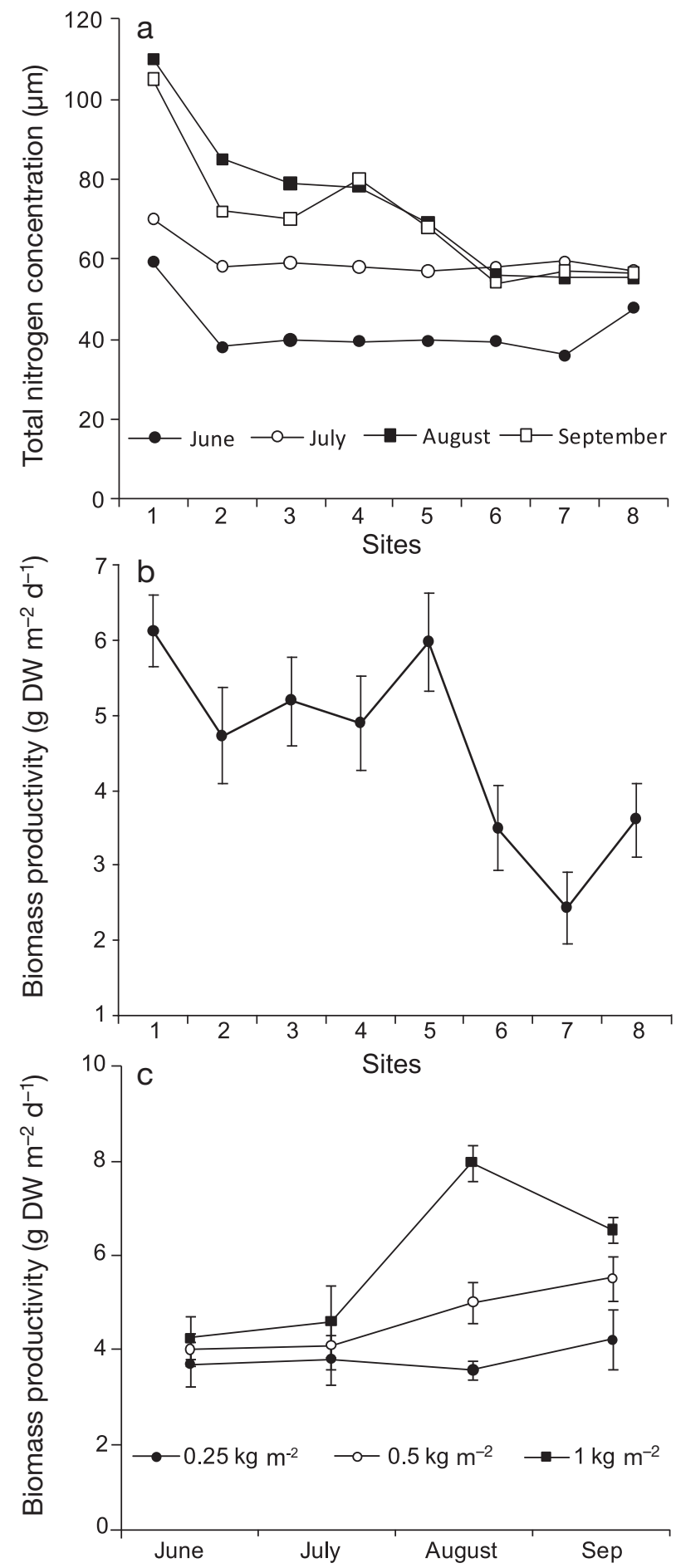

Fig. 2. (a) Total nitrogen concentration for each of the 8 culture sites around the settlement pond for $4 \mathrm{mo}$, from June to September ( $\mathrm{n}=1$ for each Site $\times$ Month). (b) Mean productivity ( $\pm 1 \mathrm{SE}$ ) of Cladophora coelothrix across 3 stocking densities at the 8 different positions (sites) within the settlement pond ( $\mathrm{n}=12$ for each site). Data show mean values of the 3 stocking densities $\left(0.25,0.5\right.$ and $\left.1 \mathrm{~kg} \mathrm{~m}^{-2}\right)$. (c) Mean productivity ( $\pm 1 \mathrm{SE}$ ) of $C$. coelothrix cultured at 3 different densities across the months between June and September ( $\mathrm{n}=3$ for each Density $\times$ Month)

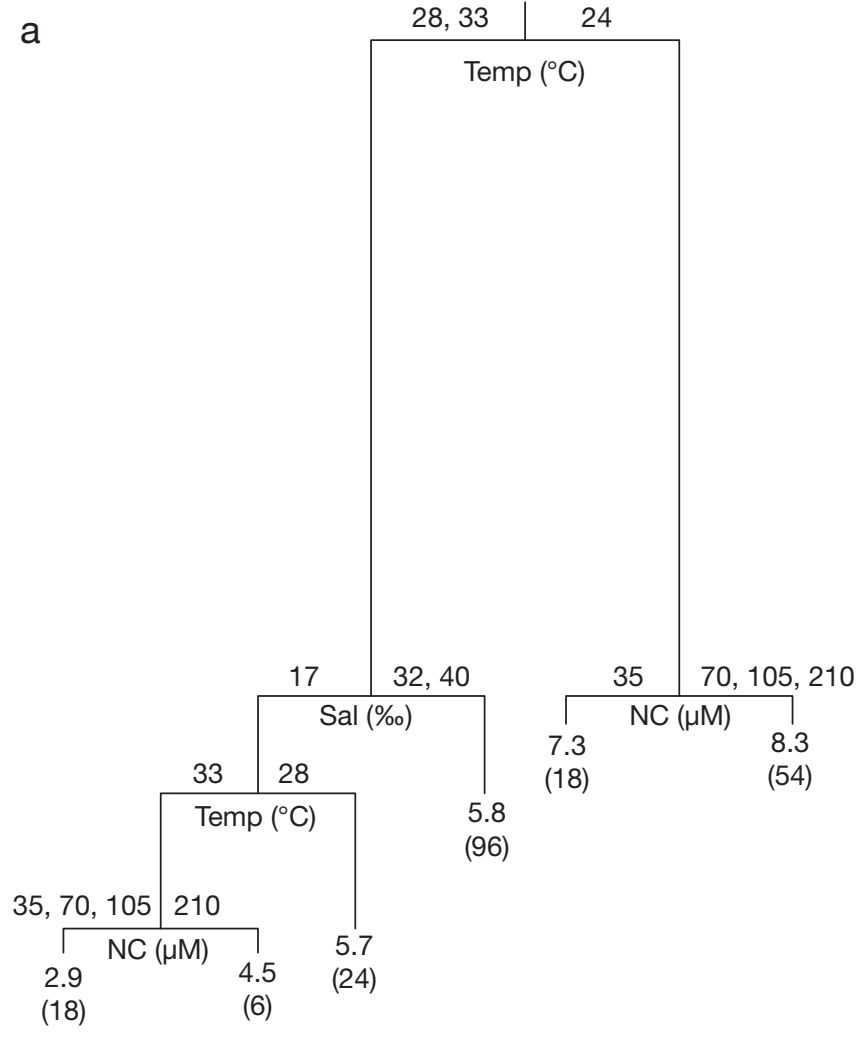

$76.3 \%$ of variability explained

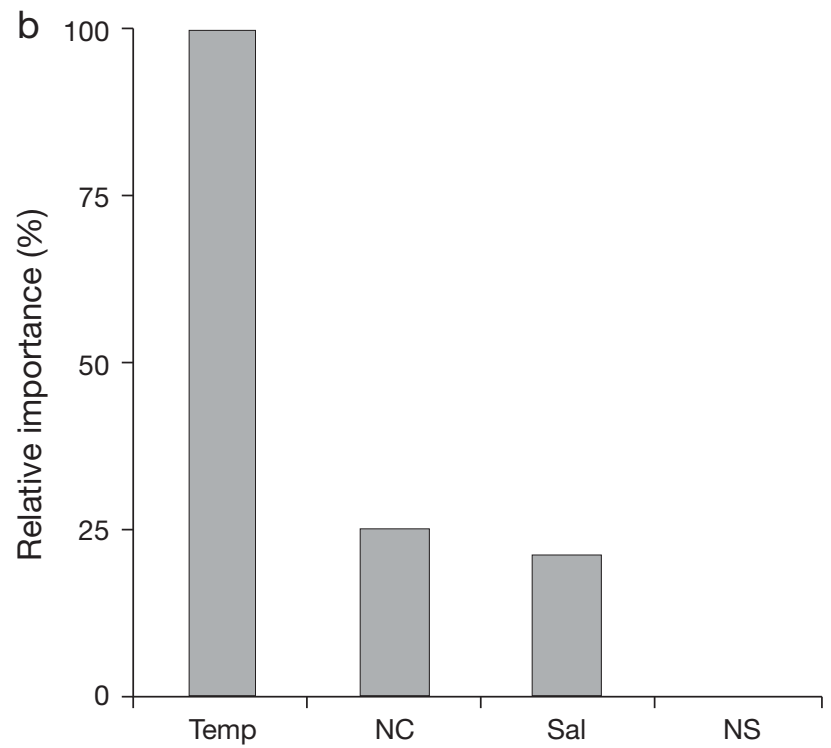

Fig. 3. (a) Univariate classification and regression trees based on environmental factors in Table 1, explaining $87 \%$ of the variation in daily growth rates (DGR). Numbers below terminal nodes are the mean DGR values (in $\% \mathrm{~d}^{-1}$ ) for the specific interaction of explanatory factors, and numbers in brackets indicate the number of cases. Explanatory factors used were: temperature (Temp; 24,28 and $\left.33^{\circ} \mathrm{C}\right)$, salinity ( $\mathrm{Sal}_{i} 17,32$ and $40 \%$ ), nitrogen concentration $\left(\mathrm{NC}_{;} 35,70,105\right.$ and $\left.210 \mu \mathrm{M}\right)$ and nitrogen source $\left(\mathrm{NS}_{\text {; }}\right.$ not represented in any terminal node). (b) Relative importance of all explanatory factors for Cladophora coelothrix in the laboratory model 
left). Overall the CART model explained $76.3 \%$ of the variability in the data. In this experiment, temperature was the most important explanatory variable (nominally 100\%; Fig. 3b) and was also the first split in the tree (Fig. 3a), splitting the annual average and high temperature treatments from the low temperature treatments. Salinity and nitrogen concentration were subsequently the most important variables for the 28 and $33^{\circ} \mathrm{C}$ split and the $24^{\circ} \mathrm{C}$ treatments, respectively (25 and $21 \%$; Fig. 3b). Nitrogen source had a negligible influence on growth, <1\% (Fig. 3b).

Nitrogen concentration was important for Cladophora coelothrix growth at low and mid-temperatures (Fig. $4 \mathrm{a}, 24^{\circ} \mathrm{C}$; Fig. 4 b, $28^{\circ} \mathrm{C}$ ). Concentrations of $70 \mu \mathrm{M}$ and above (up to $210 \mu \mathrm{M}$ ) promoted higher daily growth rates than a nitrogen concentration of $35 \mu \mathrm{M}$, regardless of the salinity or nitrogen source (Fig. 4a,b). Moreover, growth appeared to saturate with nitrogen concentration at $70 \mu \mathrm{M}$ (Fig. 4a,b). There was a marginal interaction between nitrogen concentration and salinity at low temperature $\left(24^{\circ} \mathrm{C}\right.$; Fig. 4a), which corresponds to an analogous branch split in the tree (Fig. 3a; to the right). This resulted in lower growth at low salinity and low nitrogen concentration (17\% and $35 \mu \mathrm{M})$ compared to low salinity treatments with higher nitrogen concentrations (70, 105 and $210 \mu \mathrm{M}$; Fig. 4a).

Under average to high temperatures $\left(28\right.$ and $\left.33^{\circ} \mathrm{C}\right)$, the average to high salinity (32 and $40 \%$ ) treatments grouped and were higher than any combination of low salinity treatments (Fig. 3a; branches to left). The largest, distinct combination of explanatory variables in the model related to temperature at $33^{\circ} \mathrm{C}$ and salinity at $17 \%$, with a final split between high and low nitrogen concentrations (Figs. 3a \& 4c). The low nitrogen concentrations in this split yielded the lowest overall growth rate for any treatment combination at $2.9 \% \mathrm{~d}^{-1}$. Interestingly for each 'extreme' treatment there was a split which yielded reasonable growth rates, for example, low salinity combined with average temperature $\left(28^{\circ} \mathrm{C}\right)$ yielded relatively high growth in comparison to high temperature $\left(33^{\circ} \mathrm{C}\right)$ (Fig. 3a). Similarly, where potentially negative combinations of low salinity (17\%) and high temperature $\left(33^{\circ} \mathrm{C}\right)$ existed, higher nitrogen concentrations $(210 \mu \mathrm{M})$ yielded enhanced growth compared to low nitrogen; the lowest of all treatment combinations (Fig. 3a; to the left).

At the highest temperature tested $\left(33^{\circ} \mathrm{C}\right)$, growth rates were high $\left(>5 \% \mathrm{~d}^{-1}\right)$ provided that salinity was high $(>32 \%$ o). This result was consistent irrespective of nitrogen concentration and source (Fig. 4c). The combination of extreme conditions of high tempera-
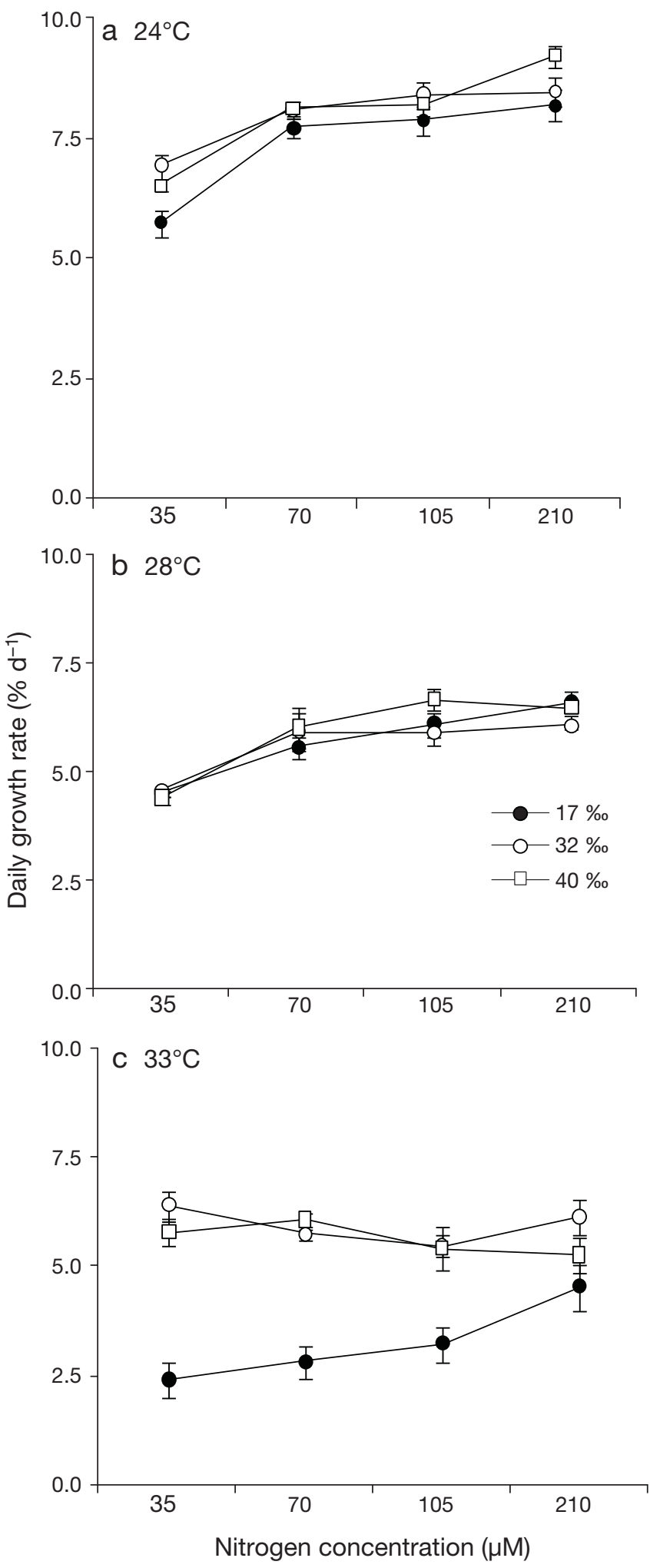

Fig. 4. Cladophora coelothrix. Growth in a combination of salinities $(17,32$ and $40 \%$ ) and nitrogen concentrations (35, 70,105 and $210 \mu \mathrm{M}$ ) at 3 different temperatures (a) $24^{\circ} \mathrm{C}$, (b) $28^{\circ} \mathrm{C}$ and (c) $33^{\circ} \mathrm{C}$. Data show mean daily growth rates of nitrate or ammonium $( \pm 1 \mathrm{SE}, \mathrm{n}=6$ ) 
ture and low salinity $\left(33^{\circ} \mathrm{C}\right.$ and $17 \%$ ), characteristic of the wet season, had the lowest overall growth rates $\left(<3 \% \mathrm{~d}^{-1}\right.$; Fig. 4c). However, these growth rates were comparable to higher salinities if cultured at the highest nitrogen concentration (e.g. $4.8 \% \mathrm{~d}^{-1}$ ) with a trend of increasing growth with increasing nitrogen at $17 \%$ (Fig. 4c).

\section{Expt 3: interactive effects of single and multiple nitrogen sources with salinity on growth}

Daily growth rates in the mesocosm experiment were always higher at $32 \%$ than at $17 \%$, irrespective of the ratio of nitrogen source available (Fig. 5a). The CART model with these 2 explanatory variables, salinity and nitrogen ratio, explained $86 \%$ of the variation in the data, and both variables were important for growth in the CART model tested (100\% vs. $85 \%$; Fig. 5b), with salinity dictating the primary branch split and nitrogen ratio driving all subsequent splits in the model (Fig. 5a). The interactions between salinity and nitrogen ratio were distinct for each salinity treatment. Under low salinity (17\%o), there was a negative influence of the 1:3 $\mathrm{NO}_{3}{ }^{-}-$ $\mathrm{N}$ :TAN treatment that yielded the lowest overall average productivity. The remaining ratio treatments then partitioned between single source and combinations (1:0 and 0:1 vs. $1: 1$ and 1:3; Figs. 5a \& 6). For higher salinity $(32 \%)$, there was a single split between single source and multiple nitrogen sources, i.e. irrespective of ratio (Figs. 5a \& 6). In general, the single source nitrogen provided the higher productivity for both salinity treatments $(16 \%$ more in $32 \%$ and $\sim 22 \%$, on average, more in $17 \%$ o).

Because Expt 3 contained only 2 factors, the tree (Fig. 5a) almost entirely reflects the trends of the mean values for each of the combination of treatments (Fig. 6). Overall, DGRs were high for most treatments, other than low salinity with single source ammonium (>10\% $\mathrm{d}^{-1}$; Fig. 6), indicating high resilience across salinities and nitrogen sources. Growth rates were higher (by $\sim 20 \%$ ) with a single nitrogen source (1:0 and 0:1) than with any combination (3:1, 1:1 and 1:3) of $\mathrm{NO}_{3}{ }^{-}-\mathrm{N}$ and TAN (Fig. 6). High salinity typically yielded higher growth rates than low salinity (32 and $17 \%$, respectively), similar to Expt 2, regardless of the $\mathrm{NO}_{3}{ }^{-}-\mathrm{N}$ :TAN (Fig. 6). Single sources of nitrogen promoted the highest daily growth rates both at high salinity $\left(15.5 \% \mathrm{~d}^{-1}\right.$ for TAN

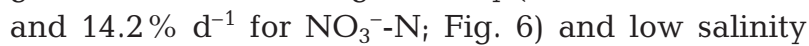
$\left(11.9 \% \mathrm{~d}^{-1}\right.$ for $\mathrm{No}_{3}{ }^{-} \mathrm{N}$ and $11.5 \% \mathrm{~d}^{-1}$ for TAN). Growth rates were lower when nitrogen was sup-

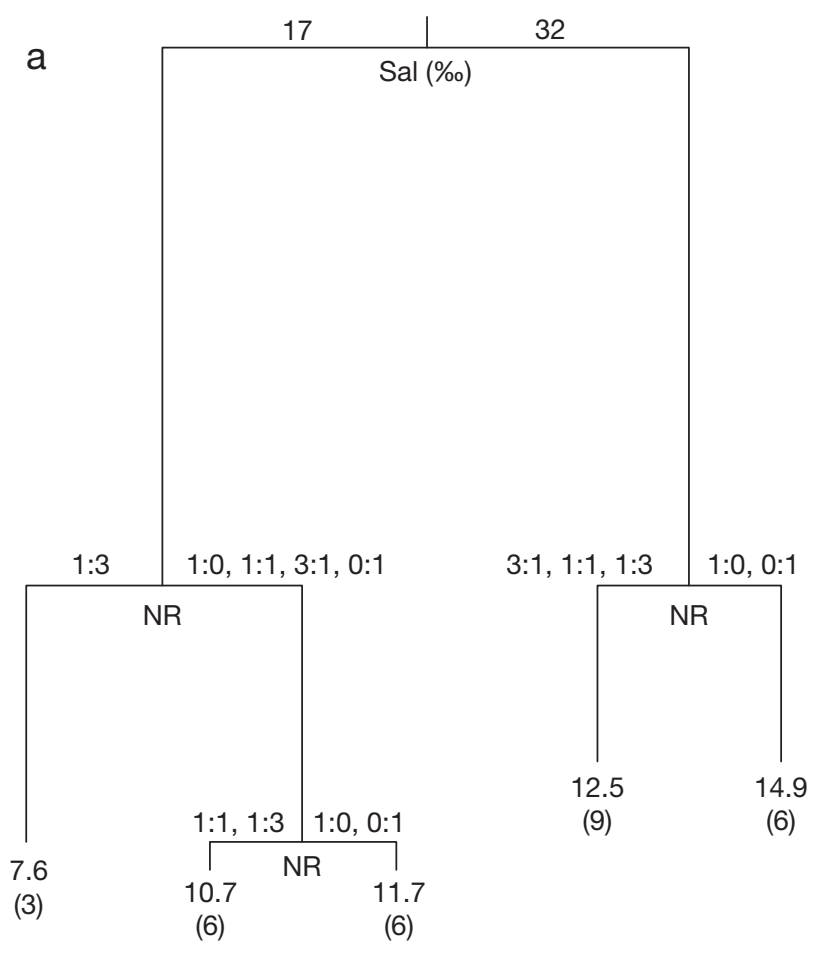

$86 \%$ variability explained

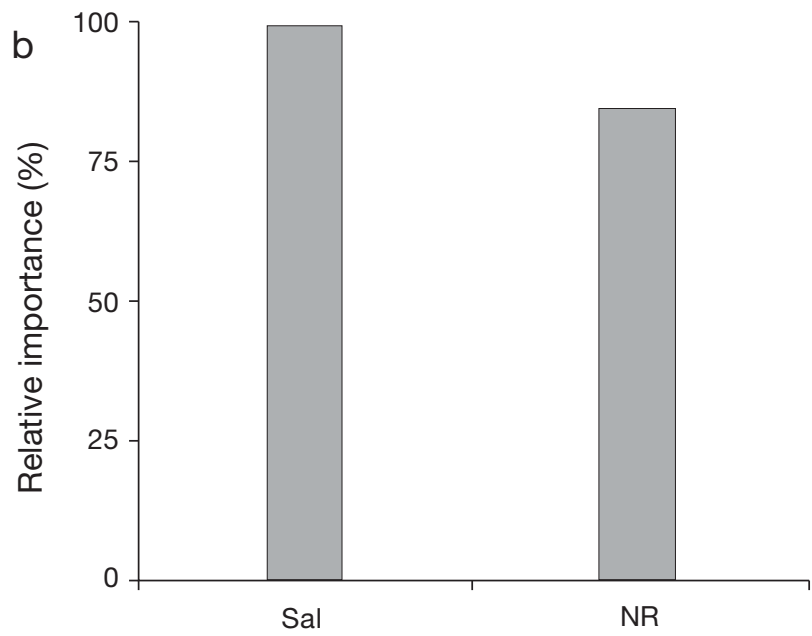

Fig. 5. (a) Univariate classification and regression tree in daily growth rates in different salinities (Sal; 17 and $32 \%$ ) and ratios of nitrate-N and total ammonium nitrogen (NR; $1: 0,3: 1$, $1: 1,1: 3$ and $0: 1$ ). Numbers below terminal nodes are the mean daily growth rates (in $\% \mathrm{~d}^{-1}$ ) for the specific interaction of explanatory factors, and numbers in brackets indicate the number of cases. The CART model explained $86 \%$ of the variability of in situ productivity. (b) Relative importance of explanatory factors for Cladophora coelothrix growth in the outdoor, controlled environment model

plied as multiple sources. At salinity $32 \%$, there was no clear difference between any combinations of nitrogen sources, whereas, at the lower salinity $(17 \%)$, growth rates were lower in the treatments 


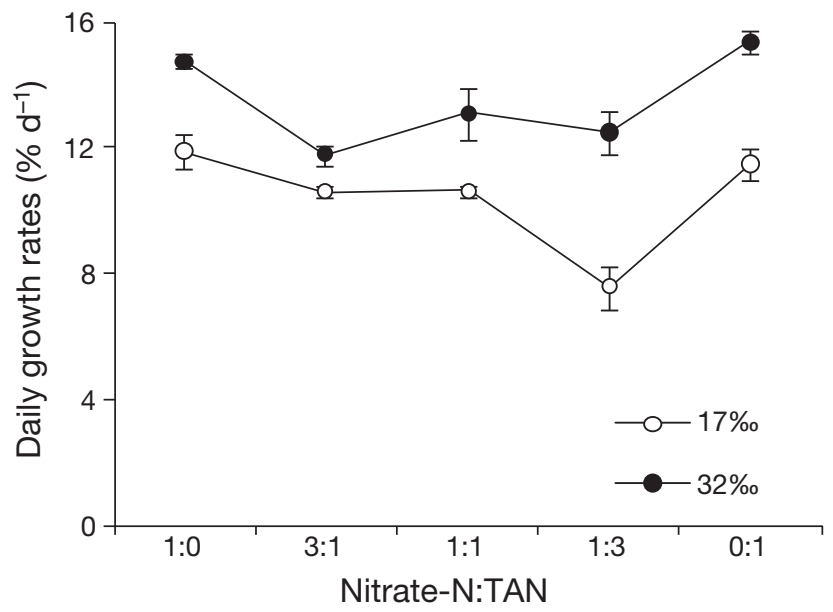

Fig. 6. Cladophora coelothrix. Daily growth rates of C. coelothrix across different nitrate- $\mathrm{N}$ and total ammonium nitrogen (TAN) ratios at 2 salinities ( $\mathrm{n}=3$ for each Species $\times$ Salinity $\times$ $\mathrm{N}$ ratios). Data show means $( \pm 1 \mathrm{SE})$

with $\mathrm{NO}_{3}{ }^{-}-\mathrm{N}$ :TAN ratios of 3:1 (Fig. 6). All of these interpretations are consistent with combinations of salinities and nitrogen ratios from the CART output (Fig. 5a).

\section{Comparison of growth and productivity between experiments}

The CART models developed for Expts 1 to 3 constitute a valuable tool for quantitatively assessing the response of a species to dynamic environmental conditions. We used data derived from experiments at 3 different scales, from in situ cultures through to controlled environment experiments. Even though the in situ experiment only ran for $4 \mathrm{mo}$, it captured marked variation in conditions in the settlement pond (temperature $\sim 24$ to $28^{\circ} \mathrm{C}$, salinity $\sim 32$ to $40 \%$ and nitrogen concentration $\sim 35$ to $70 \mu \mathrm{M}$ ), as well as highlighting management tools for the system (e.g. position within the pond and stocking densities). The controlled environment model from Expt 2, in contrast, represents the environmental variation of an entire growing season and provides an analysis of the resilience of Cladophora coelothrix in conditions relevant to this integrated system.

Each experiment had different conditions, and therefore there was no clear mechanism to correlate data across these experiments. For example, the water delivery system was different (continuous and flow-through for Expts 1 and 3, respectively, and static for Expt 2), and the stocking densities used in situ (approximately 6.8, 3.4 and $1.7 \mathrm{~g} \mathrm{l}^{-1}$ ) were higher than those for the laboratory and mesocosm experi- ments ( 1 and $0.5 \mathrm{~g} \mathrm{l}^{-1}$, respectively). Nevertheless, it is notable that the relative importance of variables from the CART models followed the same trend across the different scales of investigation, with temperature, salinity and nitrogen concentration as the main drivers of growth, albeit with some minor variations. The laboratory model (Expt 2) demonstrated that temperature was clearly the main driver of changes in growth rates throughout the year, followed by nitrogen concentration and salinity. Given that the period of the in situ trial corresponded to the lowest temperature and highest salinity, i.e. close to the optimum conditions as predicted from Expt 2, it was therefore both predicted and demonstrated that nitrogen concentration was the major driver of growth in Expt 1. All of the models demonstrated that the nitrogen source or the ratio between nitrogen sources had the least influence on growth, consistent with a strong relationship between the laboratory, mesocosm and in situ models.

\section{DISCUSSION}

One pathway for the selection of algae for biomass applications in integrated aquaculture is to utilise species that already exist and opportunistically bloom in aquaculture facilities, including green tide algae (de Paula Silva et al. 2008, Hernandez et al. 2008). In order for these species to be truly integrated, and become a reliable and commercial source of biomass, it is essential to understand the influence of seasonal changes in environmental conditions on growth, biomass yield and bioremediation potential. Here we demonstrated that the green tide alga Cladophora coelothrix is tolerant to the concurrent and extreme seasonal fluctuations in temperature, salinity, nitrogen concentrations and sources that are characteristic of tropical land-based aquaculture. Because these environmental factors typically co-vary, we used 3 scales of investigation combined with classification and regression tree analyses to partition the complex data sets and determine the relative importance of different factors under different conditions. We found that growth of C. coelothrix was sustained in most combinations of environmental factors and nitrogen (concentrations and sources), demonstrating resilience in this high-nutrient system. Furthermore, the CART models revealed that all factors influenced growth, but to different extents, with temperature as the main driver of seasonal variation in productivity. Salinity and nitrogen concentration (but not source) were also important, but only 
in conditions representative of the extremes of seasonal fluctuations. Although nitrogen was not a critical factor compared to large seasonal changes in temperature and salinity, it remained the most crucial factor for growth within a single season for the in situ experiment. The present study defines growth and resilience of an alga for integrated aquaculture across 3 scales of experimentation and provides formal models of these data as a tool for managing biomass yields in changing environments.

Seasonal fluctuations of temperature and salinity are recognized constraints for biomass production (Yang et al. 2006) and bioremediation (MarinhoSoriano et al. 2009) through integrated algal culture. This problem has been resolved or managed in some instances using alternation of species with complementary tolerance ranges across seasons (Buschmann et al. 2008, Skriptsova \& Miroshnikova 2011). Here we instead selected Cladophora coelothrix as it was a pre-adapted and reoccurring bloom-forming species, and found that it had a high environmental tolerance to both extremes of temperature and salinity that corresponded to dry winter and wet summer seasons in the tropics. These tolerances were similar to those reported for C. coelothrix in the tropics, where growth was maintained in temperatures up to $35^{\circ} \mathrm{C}$ (Cambridge et al. 1987) and salinities ranging from 15 to $45 \%$ (de Paula Silva et al. 2008). However, even if a species has a broad tolerance to any single environmental factor, stress from an additional factor may reduce overall performance (Rivers \& Peckol 1995, Lotze \& Worm 2002). Therefore, understanding and predicting the interactions between environmental factors is critical for implementing seaweedbased integrated aquaculture, particularly in open systems subject to seasonal changes in conditions (Abreu et al. 2011).

CART analyses provide a practical tool for determining the relative importance of factors that often co-vary in nature (De'ath \& Fabricius 2000) and also for partitioning factors involved in complex interactions in manipulative experiments (present study). Our results demonstrate that the interaction between environmental factors is the most critical aspect for determining species resilience in integrated aquaculture. Aquaculture in the tropics is characterized by 2 distinct seasons (wet vs. dry) which also correlate with fish production cycles (peak in the wet vs. offpeak in the dry). This leads to a simultaneous seasonal extreme of temperature $\left(33^{\circ} \mathrm{C}\right)$ and salinity $(17 \%)$ in the austral summer, an interaction that produced the lowest overall growth of Cladophora coelothrix, similar to other Cladophora species
(Thomas et al. 1988). However, the environmental stresses relating to temperature and salinity were buffered by high nitrogen concentration (Hernandez et al. 2008, present study), potentially by providing osmotic balance in the low salinities (Kamer \& Fong 2001). Alternatively, the dry season extreme (winter) in the tropics yielded conditions that were optimal for growth $\left(<28^{\circ} \mathrm{C},>32 \%\right)$, even at relatively low nitrogen concentrations $(35 \mu \mathrm{M})$. Our CART model based on the controlled environment component predicted that the optimal conditions for C. coelothrix are temperatures from $\sim 24$ to $28^{\circ} \mathrm{C}$ and salinities from $\sim 32$ to $40 \%$. This was confirmed in situ for 4 mo (June to September, austral winter), where high productivity was achieved for biomass cultured in the settlement pond, and highlights, in this case, the importance of nitrogen concentration as a driver of productivity when temperature and salinity are close to optimal.

Adequate nitrogen supply is essential to sustain high biomass productivity in seaweed-based integrated culture systems (Harrison \& Hurd 2001). Nitrogen concentration was the most important factor in the in situ experiment, where it doubled in concentration over the $4 \mathrm{mo}$ (from June to September), and was also the factor with the highest spatial variability in the settlement pond. Correspondingly, productivity was higher in August and September than in July and July, as nitrogen concentrations were low in the latter period. Within the pond, higher productivity was achieved in sites receiving effluent with higher nitrogen concentration. Similar large effects of nitrogen concentration are seen for other integrated species (Matos et al. 2006, Schuenhoff et al. 2006, Paul \& de Nys 2008), indicating it can commonly be a limiting factor even for integrated systems. However, even when nitrogen is not limiting, it may still have a role in maintaining growth rates under extreme conditions (Dodds \& Gudder 1992).

Clearly an ability to tolerate high and variable nitrogen concentrations is an advantage in integrated algal culture systems, and this includes tolerance of specific nitrogen sources such as the high ammonium concentrations from fish production (Neori et al. 2004, Phillips \& Hurd 2003). However, the CART models show that nitrogen sources (nitrate or ammonium, single source or in combination) had less influence on productivity than total nitrogen concentration. The ratio of nitrate to ammonium in situ was highly variable, yet there were no clear preferences for either nitrogen source. In theory, growth with ammonium as a nitrogen source should be higher than nitrate, because ammonium ions diffuse through the cellular membrane, whereas nitrate 
uptake incurs a cost through enzymatic reactions (Raven et al. 1992). This lack of preference for a nitrogen source is a common feature across a broad taxonomic range of algae (Navarro-Angulo \& Robledo 1999, Carmona et al. 2006), and it is likely that Cladophora coelothrix can utilize nitrate and ammonium simultaneously (Phillips \& Hurd 2003, Cohen \& Fong 2004) or sequentially (Neori 1996). Our manipulative experiments revealed that it was not the preference for nitrate or ammonium that was important, but the co-supply of multiple sources that reduced growth below potential. Therefore, full growth potential is unlikely to be achieved in this treatment pond, or any pond where ammonium has not been oxidised to nitrate. The explanation for this antagonistic result is that ammonium can inhibit nitrate uptake by inactivating or slowing the synthesis of nitrate reductase (Berges et al. 1995, Young et al. 2005), even at low concentrations $(<5 \mu \mathrm{M})$ (Thomas \& Harrison 1987). Enhancing the oxidation of ammonium to nitrate by denitrifying bacteria using biofilters could be an important strategy to complement existing conversions in order to increase the nitrate to total ammonium nitrogen ratio $>1: 3$, as even this ratio was detrimental in our study. Furthermore, values in situ commonly reach 2:1 during times of the year where environmental factors are optimal and therefore algal productivities may be significantly enhanced.

Implementation of large-scale effluent bioremediation must be supported by appropriate models suitable for up-scaling to annual productivity and bioremediation (Troell et al. 2003). Here, we used defined experimental designs to create predictive CART models that assess the relative importance of multiple, co-varying environmental variables for algal growth in an integrated system. The controlled environment model captured the seasonal trends in algal productivity over an entire annual cycle, and, importantly, the relevant output of this model was consistent with the in situ experiment in the operational settlement pond. The experimental design used in our study is similar to that used for extrapolation to commercial scenarios (Troell et al. 2003). Therefore, at the maximum productivity of $8.5 \mathrm{~g} \mathrm{DW} \mathrm{m}^{-2} \mathrm{~d}^{-1}$, the system would produce $31 \mathrm{t} \mathrm{ha}^{-1} \mathrm{yr}^{-1}$, which is equivalent to $2.5 \mathrm{t} \mathrm{ha}^{-1} \mathrm{mo}^{-1}$. At this site the integrated algal system using Cladophora coelothrix could remove $72.5 \mathrm{~kg} \mathrm{ha}^{-1}$ of nitrogen per month (at $2.9 \%$ nitrogen of dry weight; de Paula Silva et al. 2008). The maximum productivity and bioremediation that can be achieved using this integrated pond system is comparable (Msuya et al. 2006) or higher (Marinho-
Soriano et al. 2009) than others, however, not as high as intensive algal culture using aeration and high water exchange (Abreu et al. 2011). Therefore, the addition of paddlewheels in the settlement pond for aeration and water flow could provide a means to enhance spatial productivity and could also enhance the conversion of ammonium to nitrate in the water column. However, these energy-intensive strategies would be better placed if there were an additional economic driver for the biomass, for example, the productivity and nitrogen content of the C. coelothrix biomass was high enough to promote use as biochar (Bird et al. 2011, 2012) or conversion to biofuels (Zhou et al. 2010). Given the formidable task of operational management of temperature and salinity in large, multiple hectare bioremediation areas, the selection of resilient algal species is fundamental to delivering effective and reliable biomass and bioremediation within integrated tropical land-based aquaculture.

Acknowledgements. This research is part of the MBD Energy Research and Development program for Biological Carbon Capture and Storage. The project was supported by the Advanced Manufacturing Cooperative Research Centre (AMCRC), funded through the Australian Government's Cooperative Research Centre Scheme. Pedro H. de Paula Silva was supported by an AMCRC PhD scholarship. We thank Good Fortune Bay Fisheries Ltd for the use of facilities and permission to publish data, and the MARFU staff at James Cook University for their assistance on algal culture maintenance and experiments. We also thank Associate Professor Marcus Sheaves and Miss Lorenna Machado for their advice on statistical analysis, and volunteers Miss Sarah Castine and Mr. Scott Seymour for assistance with field work.

\section{LITERATURE CITED}

Abreu MH, Varela DA, Henriquez L, Villarroel A, Yarish C, Sousa-Pinto I, Buschmann AH (2009) Traditional vs. integrated multi-trophic aquaculture of Gracilaria chilensis C. J. Bird, J. McLachlan \& E. C. Oliveira: productivity and physiological performance. Aquaculture 293: 211-220

Abreu MH, Pereira R, Yarish C, Buschmann AH, SousaPinto I (2011) IMTA with Gracilaria vermiculophylla: productivity and nutrient removal performance of the seaweed in a land-based pilot scale system. Aquaculture 312:77-87

Berges JA, Cochlan WP, Harrison PJ (1995) Laboratory and field response of algal nitrate reductase to diel periodicity in irradiance, nitrate exhaustion, and the presence of ammonium. Mar Ecol Prog Ser 124:259-269

Bird MI, Wurster CM, de Paula Siva PH, Bass AM, de Nys R (2011) Algal biochar-production and properties. Bioresour Technol 102:1886-1891 
Bird MI, Wurster CM, de Paula Siva PH, Paul NA, de Nys R (2012) Algal biochar: effects and applications. GCB Bioenergy 4:61-69

Buschmann AH, Varela DA, Hernández-González MC, Huovinen P (2008) Opportunities and challenges for the development of an integrated seaweed-based aquaculture activity in Chile: determined the physiological capabilities Macrocystis and Gracilaria as biofilters. J Appl Phycol 20:517-577

> Cambridge ML, Breeman AM, Kraak S, Vandenhoek C (1987) Temperature responses of tropical to warm water Cladophora species in relation to their distribution in the North-Atlantic Ocean. Helgol Meersunters 41: 329-354

> Carmona R, Kraemer GP, Yarish C (2006) Exploring Northeast American and Asian species of Porphyra for use in an integrated finfish-algal aquaculture system. Aquaculture 252:54-65

Cohen RA, Fong P (2004) Nitrogen uptake and assimilation in Enteromorpha intestinalis (L.) Link (Chlorophyta): using ${ }^{15} \mathrm{~N}$ to determine preference during simultaneous pulses of nitrate and ammonium. J Exp Mar Biol Ecol 309:67-77

Crab R, Avnimelech Y, Defoirdt T, Bossier P, Verstraete W (2007) Nitrogen removal techniques in aquaculture for a sustainable production. Aquaculture 270:1-14

de Paula Silva PH, McBride S, de Nys R, Paul NA (2008) Integrating filamentous 'green tide' algae into tropical pond-based aquaculture. Aquaculture 284:74-80

De'ath G (2002) Multivariate regression trees: a new technique for modeling species-environment relationships. Ecology 83:1105-1117

> De'ath G, Fabricius KE (2000) Classification and regression trees: a powerful yet simple technique for ecological data analysis. Ecology 81:3178-3192

Department of Environment and Resource Management (2011) Licensing wastewater releases from existing marine prawn farms in Queensland. Available at: www. ehp.qld.gov.au/register/p00675aa.pdf (accessed 31 July 2012)

> Dodds WK, Gudder DA (1992) The ecology of Cladophora. J Phycol 28:415-427

$>$ Dortch Q (1990) The interaction between ammonium and nitrate uptake in phytoplankton. Mar Ecol Prog Ser 61: 183-201

> Fletcher RL (1995) Epiphytism and fouling in Gracilaria cultivation: an overview. J Appl Phycol 7:325-333

> Guillard RRL, Ryther JH (1962) Studies of marine planktonic diatoms. I. Cyclotella nana Hustedt and Detonula confervacea Cleve. Can J Microbiol 8:229-239

Guiry MD, Guiry GM (2012) AlgaeBase. World-wide electronic publication, National University of Ireland, Galway. Available at: www.algaebase.org (accessed 1 May 2012)

Harrison PJ, Hurd CL (2001) Nutrient physiology of seaweeds: application of concepts to aquaculture. Cah Biol Mar 42:71-82

> Hernandez I, Perez-Pastor A, Mateo JJ, Megina C, Vergara JJ (2008) Growth dynamics of Ulva rotundata (chlorophyta) in a fish farm: implications for biomitigation at a large scale. J Phycol 44:1080-1089

Kamer K, Fong P (2001) Nitrogen enrichment ameliorates the negative effects of reduced salinity on the green macroalga Enteromorpha intestinalis. Mar Ecol Prog Ser 218:87-93
Lavery PS, McComb AJ (1991) The nutritional ecophysiology of Chaetomorpha linum and Ulva rigida in Peel Inlet Western Australia. Bot Mar 34:251-260

Lin DT, Fong P (2008) Macroalgal bioindicators (growth, tissue $N, \delta^{15} \mathrm{~N}$ ) detect nutrient enrichment from shrimp farm effluent entering Opunohu Bay, Moorea, French Polynesia. Mar Pollut Bull 56:245-249

Lotze HK, Worm B (2002) Complex interactions of climatic and ecological controls on macroalgal recruitment. Limnol Oceanogr 47:1734-1741

Marinho-Soriano E, Panucci RA, Carneiro MAA, Pereira DC (2009) Evaluation of Gracilaria caudata J. Agardh for bioremediation of nutrients from shrimp farming wastewater. Bioresour Technol 100:6192-6198

- Matos J, Costa S, Rodrigues A, Pereira R, Sousa Pinto I (2006) Experimental integrated aquaculture of fish and red seaweeds in northern Portugal. Aquaculture 252: $31-42$

Msuya FE, Kyewalyanga MS, Salum D (2006) The performance of the seaweed Ulva reticulata as a biofilter in a low-tech, low-cost, gravity generated water flow regime in Zanzibar, Tanzania. Aquaculture 254:284-292

> Navarro-Angulo L, Robledo D (1999) Effects of nitrogen source, N:P ratio and N-pulse concentration and frequency on the growth of Gracilaria cornea (Gracilariales, Rhodophyta) in culture. Hydrobiologia 398/399:315-320

Neori A (1996) The type of N-supply (ammonia or nitrate) determines the performance of seaweed biofilters integrated with intensive fish culture. Isr J Aquac Bamidgeh 48:19-27

Neori A, Chopin T, Troell M, Buschmann AH and others (2004) Integrated aquaculture: rationale, evolution and state of the art emphasizing seaweed biofiltration in modern mariculture. Aquaculture 231:361-391

> Pang SJ, Liu F, Shan TF, Xu N and others (2010) Tracking the algal origin of the Ulva bloom in the Yellow Sea by a combination of molecular, morphological and physiological analyses. Mar Environ Res 69:207-215

Paul NA, de Nys R (2008) Promise and pitfalls of locally abundant seaweed as biofilters for integrated aquaculture. Aquaculture 281:49-55

> Pedersen MF, Borum J (1997) Nutrient control of estuarine macroalgae: growth strategy and the balance between nitrogen requirements and uptake. Mar Ecol Prog Ser 161:155-163

Phillips JC, Hurd CL (2003) Nitrogen ecophysiology of intertidal seaweeds from New Zealand: $\mathrm{N}$ uptake, storage and utilisation in relation to shore position and season. Mar Ecol Prog Ser 264:31-48

> Raven JA, Taylor R (2003) Macroalgal growth in nutrientenriched estuaries: a biogeochemical and evolutionary perspective. Water Air Soil Pollut 3:7-26

> Raven JA, Wollenweber B, Handley LL (1992) A comparison of ammonium and nitrate as nitrogen-sources for photolithotrophs. New Phytol 121:19-32

> Rivers JS, Peckol P (1995) Summer decline of Ulva lactuca (Clohophyta) in a eutrophic embayment-interactive effects of temperature and nitrogen availability. J Phycol 31:223-228

Sarà G (2007) A meta-analysis on the ecological effects of aquaculture on the water column: dissolved nutrients. Mar Environ Res 63:390-408

Schuenhoff A, Mata L, Santos R (2006) The tetrasporophyte of Asparagopsis armata as a novel seaweed biofilter. Aquaculture 252:3-11 
Skriptsova AV, Miroshnikova NV (2011) Laboratory experiment to determine the potential of two macroalgae from the Russian Far-East as biofilters for integrated multitrophic aquaculture (IMTA). Bioresour Technol 102: 3149-3154

Taylor R, Fletcher RL, Raven JA (2001) Preliminary studies on the growth of selected 'green tide' algae in laboratory culture: effects of irradiance, temperature, salinity and nutrients on growth rate. Bot Mar 44:327-336

Thomas TE, Harrison PJ (1987) Rapid ammonium uptake and nitrogen interactions in five intertidal seaweeds grown under field conditions. J Exp Mar Biol Ecol 107:1-8

Thomas DN, Collins JC, Russell G (1988) Interactive effects of temperature and salinity upon net photosynthesis of Cladophora glomerata (L) Kutz and Cladophora rupestris (L) Kutz. Bot Mar 31:73-77

Troell M (2009) Integrated marine and brackish water aquaculture in tropical regions: research, implementation and

Editorial responsibility: Alejandro Buschmann,

Puerto Montt, Chile prospects. In: Soto D (ed) Integrated mariculture: global review. FAO Fisheries and Aquaculture Tech Pap No. 529. FAO, Rome, p 47-131

Troell M, Halling C, Neori A, Chopin T, Buschmann AH, Kautsky N, Yarish C (2003) Integrated mariculture: asking the right questions. Aquaculture 226:69-90

Yang YF, Fei XG, Song JM, Hu HY, Wang GC, Chung IK (2006) Growth of Gracilaria lemaneiformis under different cultivation conditions and its effects on nutrient removal in Chinese coastal waters. Aquaculture 254: 248-255

> Young EB, Lavery PS, van Elven B, Dring MJ, Berges JA (2005) Nitrate reductase activity in macroalgae and its vertical distribution in macroalgal epiphytes of seagrasses. Mar Ecol Prog Ser 288:103-114

Zhou D, Zhang L, Zhang S, Fu H, Chen J (2010) Hydrothermal liquefaction of macroalgae Enteromorpha prolifera to bio-oil. Energy Fuels 24:4054-4061

Submitted: November 16, 2011; Accepted: June 24, 2012

Proofs received from author(s): August 2, 2012 